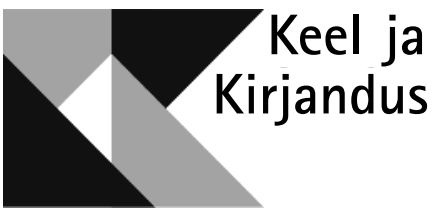

\title{
RAKENDUSLINGVISTIKA - MIS SEE ON?
}

\author{
MARGIT LANGEMETS
}

K ui Keele ja Kirjanduse toimetaja Joel Sang tegi aasta tagasi mulle ettepaneku panna kokku rakenduslingvistikateemaline kaksiknumber, olin esiotsa nõutu, sest - mis see rakenduslingvistika on? Pole olemas rakenduslingvistika ala kui sellist, pole rakenduslingvistika teooriat ega midagi ligilähedast. Ometi on ka meil ligi kümme aastat olemas rakenduslingvistika ühing, ilmub eelretsenseeritav „Eesti Rakenduslingvistika Ühingu aastaraamat" ning toimuvad iga-aastased rakenduslingvistika kevadkonverentsid, kuhu koguneb suur hulk milleg ag i tegelevaid uurijaid.

Sama küsimus - mis on rakenduslingvistika? - on painanud ka muud maailma, ennekõike rakenduslingviste endid. Siinse ajakirja avaartiklis vaeb saksa rakenduslingvistika professor Karlfried Knapp rakenduslingvistika staatust ja olemust mitmest vaatenurgast, alustades sellest, kas rakenduslingvistika on akadeemiline distsipliin. Rakenduslingvistika uurimisviisi ehk teooria ja praktika vahekorda kaaludes leiab ta (teistele uurijatele toetudes), et moodne lingvistika on ise oma uurimisala sedavõrd kitsendanud, et keele elulist mitmekesisust ja komplekssust saab hõlmata just rakenduslingvistika. Knapp tõrgub rakenduslingvistikat pidamast pelgalt „rakendatud lingvistikaks”, s.t teatava teooria rakenduseks praktikas. Ta analüüsib rakenduslingvistika võimalikku kohta teooria ja praktika vahendajana; seejärel tõestab korpuslingvistika ja õppeleksikograafia, samuti suhtluse sotsiolingvistika ja funktsionaalse pragmaatika näitel -, kuidas on alustatud praktikast, argielust, ja jõutud uute iseseisvate (rakenduslingvistiliste?) teooriateni, mis võistlevad traditsiooniliste lingvistikateooriatega. 
Knapp rõhutab ka seda, et rakenduslingvistikat ei ole ammu enam paslik samastada pelgalt võõrkeele, eriti inglise keele õpetamise ja õppimise problemaatikaga, mis vähemalt varasemal ajal oli iseäranis levinud ingliskeelses kirjanduses. Saksamaal ja teistes inglise keeleruumist väljapoole jäävates maades (aastate möödudes ka ingliskeelses maailmas endas) on terminit rakenduslingvistika pruugitud laiemalt, pidades silmas üldisemaid sotsiaalseid nähtusi ja protsesse. Nüüdisajal koondab rakenduslingvistika paljusid keeleprobleeme ja vaatenurki: mitmekeelsust, leksikograafiat, korpuslingvistikat, tõlkimist, keeletehnoloogiat, keelepoliitikat, ametisuhtlust ja paljupalju muud. Peale lingvistika on rakenduslingvistika huvi alla nihkunud ka muud alad: psühholoogia, sotsioloogia, antropoloogia, politoloogia, kognitiivteadused ja infotehnoloogia, kui nimetada mõnda.

Knappi võtmes jätkab Krista Kerge, kes küsib, kust jookseb rakenduslingvistika ja muu lingvistika piir ning kas seda on üldse vaja? Kerge meelest pole keel lingvistika jaoks autonoomne struktuur, vaid keele- ja tekstinormid on liik ühiskonna- ja kultuurinorme. Oluline on, et asjatundja - nt keeleõpetaja, tõlkija, leksikograaf, keeletehnoloog, suhtekorraldaja vm - toetaks omal alal ja omal viisil keelelist suhtlust. Kerge rõhutab rakenduslingvistika rolli teooria ja praktika vahendajana: „Rakenduslingvistikas peavad kokku saama lingvistika ja hallatava keelekasutusvaldkonna teadmised ja kogemus.” Kerge tunneb muret kahe asja pärast: mis toimub Eesti ühiskonnas ja mis toimub eesti lingvistikas.

Kerge näeb eesti keele keset hajumas, ühiskeele piire ahenemas. Eestikeelne teadus peaks hoidma eestikeelse üldhariduse, s.t kooli- ja meediahariduse, tasemel ning soodustama eestikeelset koolkondlikku keeleteadust ning iga doktori (eestikeelset) eksperdirolli oma riigis. Kuni teadus- ja hariduspoliitika pole üldiselt sirgeselgne, on teadmispõhine Eesti lihtsalt loosung. Kuigi tegelikult on fookuses mitu keelt, sest info allikad on mitmes keeles, on emakeeleainetel nii keele- ja tekstiteadlikkuse kui ka stiilitundlikkuse loojana väga oluline roll. Mida me emakeeles ei taju ega oska sobivas vormis väljendada, seda ei saa ka võõrkeeles omandada. Mis puutub seisukohta, kas lingvistika üldse enam rakenduse-täiendit vajabki, siis arvab Kerge, et seda on vaja küll ning et rakenduslingvistika erialasid tuleks lausa ühekaupa ülikoolis õpetada.

Ülejäänud artiklid käsitlevad rakenduslingvistika eri suundi (muidugi üksnes piskut sellest tohutu suurest valikust, mida on loetlenud Knapp oma avaartiklis): leksikograafiat, emakeeleõpet, kõnetehnoloogiat, mitmekeelsust ja suhtlusanalüüsi. Seega on määratult palju rohkem seda, mis jääb selle köite mõttes peitu. Valikust on seekord välja jäänud isegi n-ö esimene rakenduslingvistika valdkond - võõrkeele õpetamine. Tõsi, eesti keele kui võõrkeele õpetamist on ühe aspektina silmas peetud kõnetehnoloogilise aktsendikorpuse loomisel. Mõneti ootamatult ongi siinses valikus teistest rohkem esil kõnetehnoloogia, mida puudutab kaks, tinglikult isegi kolm artiklit: Hille Pajupuu kirjeldab emotsioonikorpuse ning Einar ja Lya Meister aktsendikorpuse loomist; Ene Vainiku artikkel seostub samuti emotsioonidega, kuigi analüüsitakse teksti, täpsemalt sõnavara. Kõnekorpuste esindatuse põhjal ei saa samas mingil juhul väita, nagu oleks sellega kaetud kogu korpuslingvistika temaatika. Kirjakeele jm allkeelte korpused on täiesti omaette teema. 
Kui lähemalt uurida „Eesti Rakenduslingvistika Ühingu aastaraamatus”1 esindatud teemasid, siis kõige rohkem on käsitletud võõrkeeleõpet ja suhtlusanalüüsi, kolmandana n-ö puhtlingvistilisi probleeme. Alad, mis rakenduslingvistika aastaraamatus on esindatud, kuid siin praegu puuduvad, on näiteks: võõrkeeleõpe, terminoloogia, lapsekeel, tõlkimine, sotsiolingvistika, viipekeel, keelepoliitika, korpuslingvistika jm. Klaari pildi saamiseks rakenduslingvistika ajaloost, arengust ja (moodsatest) suundadest soovitan igal juhul tutvuda Karlfried Knappi ülevaatliku avaartikliga.

Järgnevas on lähemalt tutvustatud teisi siinseid artikleid.

Margit Langemets vaeb taas leksikograafia ja lingvistika vahekorda, keskendudes seekord mitte niivõrd lingvistikale ehk sõnaraamatu sisule (lingvistilisele infole), kuivõrd leksikograafiale kui tugevalt rakenduslikule alale, s.t rohkem sõnaraamatu sisu esitusele, aga samavõrra ka kasutajale. Autor püüab kriitilise pilguga vaadelda ühe koolkonna, Taani Århusi Ülikooli sõnaraamatukeskuse ümber koondunud inimeste arusaama tänapäevasest sõnaraamatutööst. Autor ei jaga nende vaenulikku suhtumist lingvistikasse ja teoreetilisse leksikograafiasse, mida nad iseloomustavad sõnapaariga „lingvistiline kolonialism”, samal ajal on nende üdini praktilises (rakenduslikus) sõnaraamatukäsitluses palju häid ideid, mis vääriksid ülevõtmist.

Emakeeleõpetuse osas küsib Martin Ehala provokatiivselt: „Kui vajalik on grammatika?” Autor lähtub tõdemusest, et hea kirjakeeleoskus on osa ühiskondlikust võimumehhanismist, ning et see pädeb nii kirjakeele kui ka erialakeelte osas. Nii nagu juristid, harrastavad ka keeleteadlased oma erialakeele piiriküsimustes võimuvõitlust, olles omandanud monopoli kirjakeele normide kehtestamisele ja kirjeldamisele. Nende erialakeel ei võimalda aga tavainimesel nüanssides orienteeruda, mistõttu läheb pidevalt vaja asjatundjate ehk lingvistide endi abi, et inimesi nõustada, koolitada ja tekste keeleliselt toimetada. Ehala sõnutsi on keeleteadlased nagu „keelelised pankurid, kes teistele kuuluvalt kapitalilt oma protsendi võtavad”. Oma kaastöös analüüsib Ehala rakenduslingvisti positsioonilt, kuidas norme tavakasutajate jaoks arusaadaval viisil sõnastada ja/või õpetada, ehk teisisõnu, kuidas õpetada kirjakeelt ilma grammatikapõhiste reegliteta. Ehala meelest lähtuvad (peaksid lähtuma) kirjavahemärgistiku põhimõtted eeskätt semantilistest kriteeriumidest, samas kirja on nad pandud grammatika terminoloogias. Ma ei varjagi, et mulle on sümpaatne tema ettepanek keskenduda pigem „sõnavaraarendusele, mille üheks oluliseks eesmärgiks peaks olema kujundada harjumus kasutada elektroonilist „Eesti keele seletavat sõnaraamatut”. Sest ainus viis kahtluse korral õige vormi leidmiseks on kasutada sõnaraamatut." Ja mõned iseärasused tuleb lihtsalt ära õppida.

Hille Pajupuu valgustab kõnetehnoloogia ühe osa, inimese ja masina suhtluse emotsionaalsemaks muutmise seisu meil ja mujal. Kuigi tehnoloogiliste vahendite kasutamine muutub teatavas mõttes aina lihtsamaks, „tunnevad inimesed nendega kokku puutudes ikkagi frustratsiooni” ning üks võimalus seda vältida, on tegelda emotsioonitöötlusega. Kui varem kujutasid emotsioonid endast kõnevaldkonna eksootilist kõrvalharu, siis viimase 15 aastaga on emotsioone tõlgendava ja väljendava arvuti idee muutnud selle lausa peavooluteemaks. Põhjalik ülevaade antakse emotsioonikorpustest, sest „emotsioonitöötlus poleks mõeldav ilma emotsionaalse kõne korpusteta”. Eesti alus-

1 ERÜ ajakirjad http://www.rakenduslingvistika.ee/ajakirjad/ (20. VIII 2012). 
tas emotsionaalse kõne korpuse loomist Eesti Keele Instituudis 2006. aastal, eeskätt peeti toona silmas emotsionaalset kõnesünteesi. Pajupuu määratleb Eesti koha emotsionaalse kõne uurimises ja emotsioonitöötluses mitmest nurgast: emotsioonikorpuse, emotsioonide taju, emotsioonide akustika ning emotsionaalse kõnesünteesi ja emotsioonituvastuse seisukohalt.

Emotsioonidega jätkab Ene Vainik, kes, lähtudes praktilisest vajadusest muuta eestikeelne kõnesüntees loomulikumaks, on pakkunud välja tekstide afektiivsuse mõõtmise meetodi. Inimene lähtub kõnes väljenduva emotsiooni äratundmisel eri keeletasanditel olevatest eri laadi infokildudest, s.t emotsioonidele ainuomast kindlat väljendusviisi pole olemas. Vainik keskendub leksikaalsele tasandile ning arutleb selle üle, millised sõnaklassid on seotud emotsioonide (ehk üldisemalt afekti) väljendamisega. Ta eeldab, nagu ta ise ütleb, optimistlikult, et ka spetsiaalselt eelmärgendamata tavatekstis leidub piisavalt teateid teksti autori võimaliku emotsiooni kohta ja see informatsioon on tekstis leksikaalselt kuidagi representeeritud, et siis rakendada arvuti seda analüüsima. Vainik on kasutusele võtnud leksikaalse afektikalduvuse mõiste, mis koondab mitmesuguste leksikaalsete üksuste erinevaid viise väljendada emotsioone. Põhimõtteliselt jagunevad need viisid kahte suurde kategooriasse vastavalt sellele, kas emotsioone esmajoones väljendatakse või kirjeldatakse. Inimese kohalolu ja sellega kaasnevat lause üldist ekspressiivsust väljendavad eeskätt funktsioonisõnad (pronoomenid, prepositsioonid, kognitiivsed sidesõnad, hüüdsõnad jm), mitte niivõrd sisusõnad. Autori põhiline sõnum ongi tõdemus, et leksikaalne afektikalduvus algab (inimese) kohalolust.

Mitmekeelsuse temaatikat käsitleb Anna Verschik, kes osutab veelahkmele ükskeelse ja mitmekeelse keeleteaduse vahel (kusjuures kaalukauss on tema meelest kaldu ükskeelse kasuks), et seejärel keskenduda keelekontaktidele, mitmekeelsete kõnelejate keeleressursside kasutamisele jms. Verschik vaatleb diskursuspragmaatilisi partikleid (sidesõnad, modaalsõnad, interjektsioonid jt) - nagu näha, kattub see kategooria vähemalt osaliselt Vainiku funktsioonisõnade kategooriaga - ning osutab, et just selliseid sõnu kopeeritakse ja laenatakse väga tihti. Verschik arutleb ka kontaktidest johtuvate keelemuutuste jäävuse üle ja tõlkelaenude rolli üle keelemuutuses, samuti sünkroonia ja diakroonia piiri üle, küsides näiteks „Kas 20 aastat on sünkroonia või juba diakroonia?” Ja nagu Vainik, rõhutab ka Verschik, et „keeled ise ei tee midagi”, vaid ikka (eri keelte) kõnelejad. Koodivahetuse uurimises on järk-järgult juurdunud arusaam, et lineaarsed piirangud (vastuolu kahe keele morfosüntaksi vahel) ei tööta universaalselt. Verschik analüüsib kahe viimase kümnendi jooksul välja pakutud kaht teoreetilist mudelit, mille abil on võimalik kirjeldada kõiki kontaktidest johtuvaid nähtusi: Lars Johansoni koodikopeerimise mudelit (1993) ning Yaron Matrasi ja Jeanette Sakeli MATja PAT-mudelit (2007). Lõpetuseks toob autor välja, et Eestis on läbi uurimata inglise-eesti keelekontaktid (nii eestlaste kui ka siin elavate ingliskeelsete välismaalaste seas), kolme kohaliku keele kontaktid, kontaktid mitmesugustes mikrokogukondades ja palju muud.

Suhtlusanalüüsi valdkonda esindab Tiit Hennoste, kes analüüsib küsimist ja vastamist, täpsemalt, küsimise vahendeid küsimises kui sotsiaalses tegevuses. Hennoste töö aluseks olev mõtteviis (mis pärineb USA sotsioloogilt ja vestlusanalüütikult John Heritage'ilt) lähtub arusaamast, et keeleanalüüsis on keskne sotsiaalne tegevus ehk teisisõnu, „eesmärk ei ole moodustada 
lauseid, vaid teha keele abil erinevaid tegevusi, küsida, tervitada, jutustada jne". Hennoste toetab Heritage'i seisukohta, et küsimuse moodustamisel on küsimuse episteemiline staatus ülimuslik vormivõtete (nt morfosüntaksi ja intonatsiooni) suhtes. Just staatussuhete alusel määratlevad inimesed, kas mingit suhtlusakti antud hetkel tõlgendatakse infosoovina või infoandjana. Knappi liigituses esindab Hennoste uurimus autonoomset teoreetilise baasiga rakenduslingvistikat, mis püüab lahendada keele ja suhtluse praktilisi probleeme.

Võõrkeeleõpet, aga pigem siiski kõnetehnoloogiat, esindavad Einar ja Lya Meister, kes kirjeldavad Tallinna Tehnikaülikooli Küberneetika Instituudis loodavat aktsendikorpust, mis sisaldab eesti keelt võõrkeelena kõnelevate inimeste hääldusnäiteid. Korpuse peamine eesmärk on pakkuda süstemaatilist ja kvaliteetset uurimismaterjali eesti keele kui võõrkeele häälduse eksperimentaalfoneetiliseks uurimiseks, kuid silmas peetakse ka võimalikke keeletehnoloogilisi rakendusi nagu näiteks kõnetuvastuse treenimine aktsendiga kõne tuvastamiseks, kõneleja emakeele automaatne tuvastamine, eesti keele hääldustreeningu programmi loomine jm. Autorid analüüsivad võrdlevalt eri emakeelega (eesti, soome ja vene) kõnelejate eesti väldete hääldust. Autorid pakuvad seletusi, miks hääldavad soome emakeelega keelejuhid teise- ja kolmandavältelisi sõnu sarnaselt eesti keelejuhtidele omase kolmandavältelise kestusmalliga, aga vene emakeelega kõnelejad sarnaselt eesti kõnelejate teisevältelise malliga. Esitatud uurimistulemused peaksid autorite arvates pakkuma mõtlemisainet ka eesti keele kui võõrkeele õpetajatele-metoodikutele, kuidas eri emakeelega õpilastele paremini õpetada eesti keele fonoloogiliste kategooriate eristamist nii tajus kui ka häälduses.

\section{Applied Linguistics?}

What is applied linguistics has been, first and foremost, a question on the mind of applied linguists themselves. The opening article by Karlfried Knapp, professor of applied linguistics from Germany, considers the status and essence of the discipline from several aspects, emphasising that to-day the discipline covers many linguistic problems and aspects, such as multilingualism, lexicography, corpus linguistics, translation, language technology, language policy, and professional communication. Krista Kerge looks for the boundary between applied linguistics and the rest, asking whether drawing such a boundary is really necessary. Her emphasis lies on the mediating role of applied linguistics between theory and practice. The rest of the articles address different tendencies of applied linguistics, notably, lexicography, mother tongue teaching, speech technology, multilingualism, and conversation analysis. The dominant subject matter of the present volume happens to be speech technology, addressed by three articles: Hille Pajupuu describes the creation process of the Emotional Speech Corpus, while Einar and Lya Meister tell us how the Foreign Accent Corpus came about. Ene Vainik's contribution has also to do with emotions, but her analysis applies to their manifestation in text, to be more exact, the emotional connotation of text words. Margit Langemets analyses the relations between lexicography and linguistics, focusing on the former as, first and foremost, an applied discipline with special requirements to the presentation of information in the dictionary, depend- 
ing on user needs. Martin Ehala provokes teachers of the mother tongue by asking how necessary grammar really is. From the position of an applied linguist, Ehala analyses the possibilities of wording and/or teaching the linguistic norm understandably for an ordinary user, in other words, how to teach the linguistic standard without using the rules formulated in the metalanguage of traditional grammar. Multilingualism is discussed by Anna Verschik, who speaks of language contacts, the use of individual language resources by plurilingual users, etc. Verschik also speculates on the sustainability of contact-based changes and on the role of translation loans in language change, as well as on the boundary of synchrony and diachrony. Conversation analysis is represented by Tiit Hennoste, who discusses the linguistic tools used in asking. Hennoste's approach (originating from the US sociologist and conversation analyst John Heritage) is based on the apprehension that conversation analysis should treat its object as a social action.

Margit Langemets (b. 1961), PhD, Institute of the Estonian Language, researcher, Head of the Dictionary Department, margit@eki.ee 